\title{
BMJ Open How do aggression source, employee characteristics and organisational response impact the relationship between workplace aggression and work and health outcomes in healthcare employees? A cross-sectional analysis of the National Health Service staff survey in England
}

Shannon Cheng (D) , 'Jeremy Dawson (D) , ${ }^{2}$ Julie Thamby, ${ }^{1}$ Winston R Liaw, ${ }^{3}$ Eden B King ${ }^{1}$

To cite: Cheng S, Dawson J, Thamby J, et al. How do aggression source, employee characteristics and organisational response impact the relationship between workplace aggression and work and health outcomes in healthcare employees? A cross-sectional analysis of the National Health Service staff survey in England. BMJ Open 2020;10:e035957. doi:10.1136/ bmjopen-2019-035957

- Prepublication history for this paper is available online. To view these files, please visit the journal online (http://dx.doi. org/10.1136/bmjopen-2019035957).

Received 25 November 2019

Revised 13 May 2020

Accepted 29 June 2020

Check for updates

(C) Author(s) (or their employer(s)) 2020. Re-use permitted under CC BY-NC. No commercial re-use. See rights and permissions. Published by BMJ.

For numbered affiliations see end of article.

Correspondence to

Shannon Cheng;

shannon.k.cheng@rice.edu

\section{ABSTRACT}

Objectives To examine the prevalence of aggression in healthcare and its association with employees' turnover intentions, health and engagement, as well as how these effects differ based on aggression source (patients vs colleagues), employee characteristics (race, gender and occupation) and organisational response to the aggression. Design Multilevel moderated regression analysis of 2010 National Health Service (NHS) survey.

Setting 147 acute NHS trusts in England.

Participants 36850 participants across three occupational groups (14\% medical/dental, $61 \%$ nursing/ midwifery, $25 \%$ allied health professionals or scientific and technical staff).

Main outcome measures Employee turnover intentions, health and work engagement.

Results Both forms of aggression (from patients and colleagues) have significant and substantial effects on turnover intentions, health and work engagement; however, for all three outcome variables, the effect of aggression from colleagues is more than twice the size of the effect of aggression from patients. Organisational response was found to buffer the negative effects of aggression from patients for turnover intentions and the negative effects of aggression from patients and colleagues for employee health. The results also demonstrated that nurses/midwives, women and Black employees are more likely to experience aggression; however, no clear patterns emerged on how aggression differentially impacts employees of different races, genders and occupations with respect to the outcome variables.

Conclusions Although aggression from patients and colleagues both have negative effects on healthcare employees' turnover intentions, health and work engagement, these negative effects are worse when

\section{Strengths and limitations of this study}

- This study uses a large, multilevel dataset from the National Health Service (NHS) to better understand the prevalence and effects of aggression in healthcare.

- We examine the effects of aggression on multiple outcomes, including employee work engagement, turnover intentions, and health, as well as how these effects may vary by employee characteristics (race, gender, occupation), aggression source (patients vs colleagues), and whether there was an organisational response to the aggression.

- The main limitations of this study were the lack of diversity in the sample (predominately white and female) and the cross-sectional nature of the data; however, the sample was representative of the healthcare workforce in the NHS, and these results provide an important foundation for future longitudinal surveys that are targeted towards addressing these issues.

it is aggression from colleagues. Having an effective organisational response can help ameliorate the negative effects of aggression on employees' health; however, it may not always buffer negative effects on turnover intentions and work engagement. Future research should examine other approaches, as well as how organisational responses and resources may need to differ based on aggression source.

\section{INTRODUCTION}

Workplace aggression, defined as harmful physical or nonphysical acts carried out 
against an individual, continues to be a prevalent issue for many healthcare professionals. ${ }^{1-5}$ For example, a recent systematic review demonstrated that over $60 \%$ of healthcare professionals have experienced workplace aggression from patients or visitors. ${ }^{4}$ In addition, although aggression is most often discussed as coming from patients and their relatives, healthcare professionals can experience these acts from their peers and supervisors as well. ${ }^{6}$ This workplace aggression can take on many forms, including verbal and non-verbal expressions of dissatisfaction, harassment, bullying and physical harm to people and property. ${ }^{6}$ And although workplace aggression is present across many industries, many of the risk factors for workplace violence, such as providing physical and emotional care for others, making decisions that influence other people's lives, and having contact with individuals under the influence of medication, are commonplace in healthcare. $^{6-9}$ As a result, when healthcare professionals experience aggression, they often regard it as part of the job; however, this does not buffer them against the negative consequences that workplace aggression can have.

Workplace aggression can have significant adverse effects for healthcare employees, patients and organisations. Healthcare professionals who experience aggression at work often have worse physical (eg, headaches, stomachaches, pain, sleep issues), psychological (eg, depression, anxiety, burnout, distress, self-esteem issues) and emotional (eg, anger, sadness, fear, guilt, powerlessness, embarrassment) outcomes than their counterparts who do not experience workplace aggression. ${ }^{10} 11$ In addition, if the aggression turns violent, employees can sustain multiple injuries, including bruises, bites, abrasions, scratches or lacerations, ${ }^{10}{ }^{12}$ which creates a work environment that is neither psychologically nor physically safe for these individuals. Experiencing workplace aggression can impact how employees feel about their work as well; research has demonstrated higher turnover intentions, more absenteeism, less job satisfaction, decreased engagement and reduced organisational commitment. ${ }^{6} 101314$ These consequences are not only detrimental to the employees; they can also significantly impact patient care. ${ }^{10} 15$ Previous work has shown that workplace aggression can result in increased medical errors, decreased time spent with patients, reduced interest in patients and decreased work productivity. ${ }^{10} 1617$ Lastly, in addition to these important costs at the employee and patient level, there are also significant financial costs at the organisational level-from employee absences, lost productivity and turnover. ${ }^{10} 1819$

Due to the enduring prevalence and impact of workplace aggression in healthcare, many researchers and practitioners have examined risk factors specific to healthcare organisations. For example, when it comes to aggression from patients, risk factors can include unmet expectations by patients (eg, denial of a patient request, delay in receiving care), insufficient personnel and equipment, communication breakdowns between healthcare employees and patients, and inefficient organisational management. ${ }^{1}{ }^{13} 20$ When it comes to aggression from colleagues (also sometimes referred to as workplace bullying), risk factors can also include interpersonal conflict, high negative affectivity, low supervisor and coworker support, role conflict and ambiguity, poor working conditions, low job control, high job demands, autocratic or laissez-faire leadership and a poor violence prevention climate. ${ }^{7-21}$ In addition, certain healthcare settings can be more prone to workplace aggression than others. Research has shown that workplace aggression is most likely to occur in psychiatric departments, emergency services, polyclinics/waiting rooms and geriatric units, ${ }^{14}$ which may be in part due to the types of patients that these healthcare employees are working with. Patients with untreated mental disorders or substance abuse, as well as older adults who are often dealing with dementia and many other chronic illnesses, have been commonly associated with aggressive and/or unpredictable behaviour-due to the conditions they are facing. ${ }^{625-27}$ Research has also examined whether certain groups of individuals are potentially more likely to face workplace aggression; for example, nurses are known to experience high rates of aggression in their day-to-day work lives. ${ }^{3}$ When it comes to other demographic variables, such as gender and race, the research is more equivocal. For example, some studies have found that female healthcare professionals are more likely than male healthcare professionals to experience workplace aggression, others have found that men are more likely to experience aggression, and others argue that it depends on the type of aggression (eg, verbal, physical, sexual). ${ }^{4628}$ Similarly, some studies have found that ethnic minority employees face more aggression than White employees, while others have found that ethnic minority employees are actually at a reduced risk for aggression. ${ }^{4629}$

In addition to the examination of risk factors and higher risk groups in healthcare settings, recommendations and best practices have been developed in order to help prevent and minimise workplace aggression. For example, Hahn $e t a l^{30}$ have developed the Strategies for Addressing Patient and Visitor Aggression in Healthcare model, which highlights strategies at the macro (community, government, society), meso (organisation) and micro (team/staff) levels. Similarly, other researchers and practitioners, as well as health and safety organisations, have provided strategies on how to prevent and address workplace aggression, such as carrying out risk assessments, adjusting environmental design issues (eg, having enough space in waiting rooms; providing adequate lighting, signage, and information; using sound-absorbing materials; keeping routes and exits clear), adjusting work and job design issues (eg, avoiding lone working, long wait times and staffing shortages, ensuring clear communication among care provider team and patients), providing education and training on how to minimise and address workplace aggression, and creating and enforcing policies on reporting and responding to workplace aggression. ${ }^{63132}$ 
However, although many advances have been made in reducing the prevalence and negative effects of aggression on healthcare employees, there are still many areas that can be further developed. For example, healthcare research has started to examine the differences between aggression from internal sources (eg, peers, supervisors) and external sources (eg, patients, visitors), ${ }^{14} 2933$ but this research comparing aggression sources is relatively sparse, and understanding the impact of different aggression sources and how they may need to be addressed differently is important. Based on theories on power and justice, the employee's relationship to the perpetrator likely impacts the effect of workplace aggression on the employee's work and health outcomes. ${ }^{34}$ For example, individuals with more power relative to the employee often have a greater ability to influence the employee's attitudes and behaviours towards the organisation, as well as their outcomes at the organisation, which can increase the detrimental effects of workplace aggression on the employee. Individuals outside of the organisation are often seen as holding less power over the employees (in comparison to individuals inside the organisation, such as supervisors and colleagues); in addition, because those outside of the organisation are not seen as reflecting the organisations' treatment of their employees, employees may be less likely to blame outsider aggression on their organisation. ${ }^{94}$ In healthcare, this effect is compounded by the high prevalence of workplace aggression from patients, which may cause healthcare employees to expect a certain degree of aggression from their patients as part of their job, and therefore, be less impacted by this aggression source.

Although the risk factors and manifestations of aggression from different sources may vary (eg, physical aggression is more common from patients, verbal aggression is common among both colleagues and patients), ${ }^{4}{ }^{14}$ it is helpful to understand how the different aggression sources may impact employee work and health outcomes and how these effects may interact with employee characteristics and organisational responses to aggression. For example, many studies have examined how the prevalence of workplace aggression differs by demographics like gender, race and occupation; however, fewer studies have examined if these different groups are impacted differently by workplace aggression and aggression source with respect to their work and health outcomes. ${ }^{29}$ This leads to our first three research questions:

Research question 1: What is the prevalence of workplace aggression from colleagues and patients by gender, race and occupation?

Research question 2: How does aggression source impact the effect of workplace aggression on turnover intentions, work engagement and health?

Research question 3: How does gender, race and occupation impact the effect of workplace aggression from colleagues and patients on turnover intentions, work engagement and health?
In addition, we are interested in building on existing research on the potentially buffering effects of organisational best practices in ameliorating the negative effects of workplace aggression. Previous research has started to examine the effects of organisational policies and perceived organisational support on work and health outcomes, such as organisational commitment and depression; ${ }^{35}{ }^{36}$ however, few studies have examined how these organisation-level variables may impact patient versus coworker aggression differently. ${ }^{29}$ It is possible that, if employees perceive aggression from patients to be outside of the organisation's control, a response from the organisation regarding the aggression would have less impact; on the other hand, because aggression from patients is viewed to be outside of the organisation's control, a response from the organisation may be a welcome surprise and have an increased positive effect in buffering against the negative effects of patient aggression. This leads to our fourth research question:

Research question 4: How does an organisational response to aggression impact the effect of workplace aggression on turnover intentions, work engagement and health, and how does aggression source (patients vs colleagues) impact the effect of an organisational response on these outcomes?

To address these gaps, we investigate aggression and employee outcomes within 147 acute trusts in the National Health Service (NHS), which allows us to aggregate results across hospitals and occupations. In this study, we describe aggression among NHS employees and how that aggression is associated with employees' turnover intentions, health and engagement. We look at two types of aggression, from patients and from colleagues, and we also explore how these relationships vary by individual characteristics, including race, gender and occupation. Furthermore, we examine if and how organisational responses influence the relationship between aggression and employees' turnover intentions, health and engagement, and if these effects differ by aggression source.

\section{METHODS \\ Context}

This study used data from the NHS in England. The NHS comprises several hundred publicly funded healthcare provider organisations, which operate semiautonomously under a centralised framework. Several different types of provider organisations exist, with the largest being called 'acute trusts', which are individual hospitals or groups of geographically close hospitals operating under joint management (and often sharing employees). To ensure some similarity of overall population, our study used data from acute trusts only.

Data were collected as part of the annual NHS staff survey, which has been compulsory in all NHS organisations since 2003. The survey includes questions on a range of work experiences including attitudes, well-being, management practices, errors and incidents, and other 
areas of climate and culture. Further information about the NHS staff survey is available at www.nhsstaffsurveys. com. In each organisation a random sample of at least 850 employees is sent questionnaires each year. We use data from the 2010 survey, which had an overall response rate of $54 \%$.

\section{Sample}

All 147 non-specialist acute trusts that were part of the NHS at the time of this study were included in the analysis. As our analysis focuses on clinical staff, we removed non-clinical staff, and staff who said they do not have frequent contact with patients (participants were asked to indicate whether they had face-to-face contact with patients as part of their job, with response options 'yes, frequently', 'yes, occasionally', or 'no'; only those who answered 'yes, frequently' were included in our analysis). This left us with 36850 responses across three broad occupational groups: $14 \%$ were medical or dental staff, $61 \%$ nursing or midwifery staff and $25 \%$ were allied health professionals (eg, occupational therapists, psychologists) or scientific and technical staff (eg, pharmacists, theatre technicians). Eighty-two per cent of respondents were female, while the same proportion described their ethnic background as White; with $10 \%$ were Asian, $5 \%$ Black, $1 \%$ of mixed ethnicity and $2 \%$ from other ethnic backgrounds. Seventeen per cent were 30 or under, $26 \%$ aged $31-40,32 \%$ aged $41-50$ and $26 \%$ over 50 .

\section{Measures}

Most of the measures from the NHS staff survey were developed specifically for that survey when it started in 2003; some were adapted from existing measures but altered to fit the NHS context following extensive pilot testing. Decisions about what questions were included in the survey were made by an NHS committee, and were a compromise between inclusivity of multiple topics and overall length. The author team did not have say over the survey items and received this data as secondary data. We acknowledge that making edits to existing measures (eg, Eight-Item Short Form Questionnaire, SF-8) or using specifically designed questions for the NHS can impact the psychometric properties of these measures; however, in each case, questions were cognitively tested before inclusion to ensure face validity, and where appropriate, scale reliability was checked with Cronbach's alpha. Measures included in this study were experienced aggression, turnover intentions, work engagement, employee health and organisational response to aggression. See table 1 for an overview of the measures, their items, response scales and scale reliabilities.

Occupational group (coded as medical/dental, nursing/midwifery and allied health professionals/scientific and technical), race (coded as white or non-white) and gender (male or female) were all used as moderating variables in some analyses, but when they were not, they were included as control variables. To reduce potential effects of sample bias, analyses also controlled for whether or not the participant was a line manager, age and length of time working at the organisation.

\section{Analysis}

Descriptive statistics (percentages experiencing aggression) were used to summarise the levels of aggression overall and by demographic/occupational groups. Due to the multilevel nature of the data, all analyses describing relationships between aggression and other variables was conducted using multilevel regression, with organisation as the level 2 grouping variable. Differences between relationships by occupational group, gender and race were analysed using individual-level moderated multilevel regression, while the effects of organisational response on relationships were examined using cross-level moderated regression. As this was a paper-based survey, some questions were left blank by some respondents. However, no main variable had more than $1.4 \%$ missing data, and no control variable more than $2.6 \%$ missing data, and therefore, listwise deletion was used for the analysis, but comparisons were made between cases included and excluded in each analysis, and no meaningful differences were found.

\section{RESULTS}

Table 2 gives the means and SD for all numerical study variables, broken down by occupational group, gender and racial group. Of particular note is that the overall aggression rates as reported by staff are high: $16 \%$ of staff report experiencing some form of aggression from colleagues within the previous year, and $25 \%$ report experiencing aggression from patients (or their relatives, or visitors to the hospital). In addition, nurses/midwives are more likely to experience aggression than other clinical staff-both from colleagues (17\% compared with $14 \%$ for medical/dental staff and $13 \%$ for allied health professionals/scientific and technical staff), and particularly from patients (31\% compared with $14 \%$ and $16 \%$, respectively). Women are more likely to experience aggression from patients (26\% compared with $20 \%$ for men), although there is no significant difference when it comes to aggression from colleagues. There are also significant differences between different racial groups with respect to both aggression variables. Table 3 shows the intercorrelations of the aggression variables with turnover intentions, work engagement, employee health and organisational response.

Table 4 shows the effects of experiencing aggression on the three individual outcomes: turnover intentions, work engagement and employee health. Both forms of aggression have significant and substantial effects on all outcomes, and in all three cases, the effect of aggression from colleagues is more than twice the size of the effect of aggression from patients. Experiencing aggression from colleagues appears to have a much more damaging effect than aggression from patients. 
Table 1 Study measures

\begin{tabular}{|c|c|c|c|}
\hline Variable & Measure items & Response scale & $\begin{array}{l}\text { Cronbach's } \\
\text { alpha }\end{array}$ \\
\hline $\begin{array}{l}\text { Experienced } \\
\text { aggression }\end{array}$ & 4 items, split into two groups: & - Yes/no & N/A \\
\hline \multirow{2}{*}{$\begin{array}{l}\text { Turnover } \\
\text { intentions }\end{array}$} & 3 items & \multirow{2}{*}{$\begin{array}{l}\text { 5-point Likert scale ('strongly } \\
\text { disagree' to 'strongly agree') }\end{array}$} & \multirow[t]{2}{*}{0.92} \\
\hline & $\begin{array}{l}\text { 'As soon as I can find another job, I will leave this } \\
\text { (organisation)' }\end{array}$ & & \\
\hline
\end{tabular}

Work
engagement
$\begin{aligned} & \text { Scale, adapted for the NHS context using cognitive } \\ & \text { testing. }\end{aligned}$
3 items
'I look forward to going to work'
'I am enthusiastic about my job'
'Time passes quickly when I am working'

Employee Taken from the SF-8 (an eight-item short form

health questionnaire measuring health-related quality of life). ${ }^{48}$

Three items

- 'Overall, how would you rate your health during the past 4 weeks?'

- 'During the past 4 weeks, how much difficulty did you have doing your daily work, both at home and away from home, because of your physical health?'

- 'During the past 4 weeks, how much did personal or emotional problems keep you from doing your usual work or other daily activities?' 5-point scale ('never,' 'rarely,'

0.78 'sometimes,' 'often,' 'always')

\begin{tabular}{|c|c|c|c|}
\hline $\begin{array}{l}\text { Organisational } \\
\text { response to } \\
\text { aggression }\end{array}$ & $\begin{array}{l}4 \text { items } \\
\text { 'My [organisation] takes effective action if staff are...' } \\
\text { relatives or other members of the public' } \\
\text { '....physically attacked by other members of staff' } \\
\text { '....bullied, harassed or abused by patients/service } \\
\text { '....bullied, harassed or abused by other members of } \\
\text { staff' }\end{array}$ & $\begin{array}{l}\text { 5-point Likert scale ('Strongly } \\
\text { disagree' to 'strongly agree') } \\
\text { Responses were aggregated to } \\
\text { the organisational level: ICC(2) } \\
\text { (intraclass correlation) was } 0.74 \text {, } \\
\text { and mean } r_{\text {wg(i) }} \text { was } 0.89 \text {, with a } \\
\text { minimum value of } 0.79 \text { (based on } \\
\text { a uniform distribution), justifying } \\
\text { aggregation statistically. }{ }^{49}\end{array}$ & 0.90 \\
\hline
\end{tabular}

NHS, National Health Service.
- The first item is assessed on a scale 0.75 ranging from 'excellent' to 'very poor'

- The second has response options: 'none at all', 'a little bit', 'some', 'quite a lot', 'could not do daily work'

The third has response options 'Not at all', 'very little', 'somewhat', 'quite a lot', 'could not do daily activities'

- Coded so that a higher score represents worse health (consistent with SF-8 scoring).

5-point Likert scale ('Strongly

Responses were aggregated to the organisational level: ICC(2) (intraclass correlation) was 0.74 , and mean $r_{\text {wo(i) }}$ was 0.89 , with a minimum value of 0.79 (based on a uniform distribution), justifying aggregation statistically. ${ }^{49}$ 
Table 2 Descriptive statistics for different groups of staff

\begin{tabular}{|c|c|c|c|c|c|c|}
\hline & $\begin{array}{l}\text { Aggression } \\
\text { from } \\
\text { colleagues, \% }\end{array}$ & $\begin{array}{l}\text { Aggression } \\
\text { from patients, } \\
\%\end{array}$ & $\begin{array}{l}\text { Turnover } \\
\text { intentions }\end{array}$ & $\begin{array}{l}\text { Work } \\
\text { engagement }\end{array}$ & $\begin{array}{l}\text { Employee } \\
\text { health }\end{array}$ & $\begin{array}{l}\text { Organisational } \\
\text { response }\end{array}$ \\
\hline Overall $(n=36850)$ & 16 & 25 & $2.52(1.04)^{\star}$ & $3.87(0.75)^{\star}$ & $\begin{array}{l}1.58 \\
(0.75)^{\star}\end{array}$ & $3.58(0.09)^{\star}$ \\
\hline \multicolumn{7}{|l|}{ Occupational group } \\
\hline Medical/dental $(n=5186)$ & 14 & 14 & 2.34 & 3.94 & 1.41 & 3.58 \\
\hline Nursing/midwifery $(n=22534)$ & 17 & 31 & 2.56 & 3.87 & 1.63 & 3.58 \\
\hline AHPs/S\&T† (n=9130) & 13 & 16 & 2.50 & 3.82 & 1.57 & 3.59 \\
\hline \multicolumn{7}{|l|}{ Gender } \\
\hline Female $(n=30010)$ & 16 & 26 & 2.52 & 3.87 & 1.60 & 3.58 \\
\hline Male $(n=6539)$ & 15 & 20 & 2.51 & 3.87 & 1.49 & 3.58 \\
\hline \multicolumn{7}{|l|}{ Racial group } \\
\hline White $(n=29915)$ & 15 & 25 & 2.52 & 3.83 & 1.58 & 3.58 \\
\hline Asian $(n=3537)$ & 18 & 18 & 2.42 & 4.13 & 1.64 & 3.57 \\
\hline Black $(n=1691)$ & 23 & 27 & 2.59 & 3.98 & 1.56 & 3.56 \\
\hline Mixed $(n=449)$ & 20 & 26 & 2.56 & 3.86 & 1.64 & 3.58 \\
\hline Other $(\mathrm{n}=727)$ & 19 & 21 & 2.61 & 3.95 & 1.58 & 3.57 \\
\hline
\end{tabular}

All differences statistically significant $(p<0.05)$ except difference between medical/dental and AHPs/S\&T in aggression from colleagues, and differences between female and male in aggression from colleagues, turnover intentions, work engagement and organisational response. ${ }^{\star}$ Mean (SD).

†Allied health professionals/scientific \& technical staff.

AHPs/S\&T, Allied health professionals/scientific and technical staff.

Tables 5-7 show the results of moderated multilevel regression with the effects of aggression moderated by occupational group, gender and race, respectively. The effect of aggression from colleagues has a stronger effect on turnover intentions for medical/dental staff and a smaller effect for nursing/midwifery staff, while the effect of aggression from patients is actually a bit smaller for medical/dental staff. The effect of aggression from colleagues is slightly larger for men than women, but the effect of aggression from patients is slightly larger for women than men. There are no differential effects on turnover intentions by race.

Table 3 Intercorrelations of aggression and numerical variables

\begin{tabular}{|c|c|c|c|c|c|}
\hline & 1 & 2 & 3 & 4 & 5 \\
\hline \multicolumn{6}{|l|}{$\begin{array}{l}\text { 1. Aggression from } \\
\text { colleagues }\end{array}$} \\
\hline $\begin{array}{l}\text { 2. Aggression from } \\
\text { patients }\end{array}$ & 0.15 & & & & \\
\hline 3. Turnover intentions & 0.24 & 0.16 & & & \\
\hline 4. Work engagement & -0.17 & -0.11 & -0.51 & & \\
\hline 5. Employee health & 0.21 & 0.14 & 0.27 & -0.27 & \\
\hline $\begin{array}{l}\text { 6. Organisational } \\
\text { response }\end{array}$ & -0.04 & -0.04 & -0.08 & 0.03 & -0.04 \\
\hline
\end{tabular}

All correlations are significant $(p<0.01)$.
For work engagement, there is a slightly smaller effect of aggression from colleagues for medical/dental staff and also for women. Non-white staff have a slightly larger (more negative) effect of aggression from patients. Effects on employee health are not found to be distinct by occupational group, but the effect of aggression from colleagues is slightly smaller for women than men, and for non-white than White staff. Non-white staff also have a greater effect of aggression from patients.

Table 8 shows the effect of aggression on the outcomes as moderated by organisational response. For turnover intentions, aggression from colleagues is not affected by organisational response, but aggression from patients is: where there is a good organisational response, employees who have experienced aggression from patients are less likely to want to leave the organisation. There are no differential effects for work engagement, but for employee health, a good organisational response mitigates the damaging effects of aggression from both patients and colleagues.

\section{DISCUSSION}

In this study, we described the aggression experienced by NHS employees, how this aggression impacts their turnover intentions, health and engagement, and how these effects are impacted by aggression source (patients vs colleagues), employee characteristics (race, gender and occupation), and whether there was an organisational 
Table 4 Effects of aggression on three outcome variables

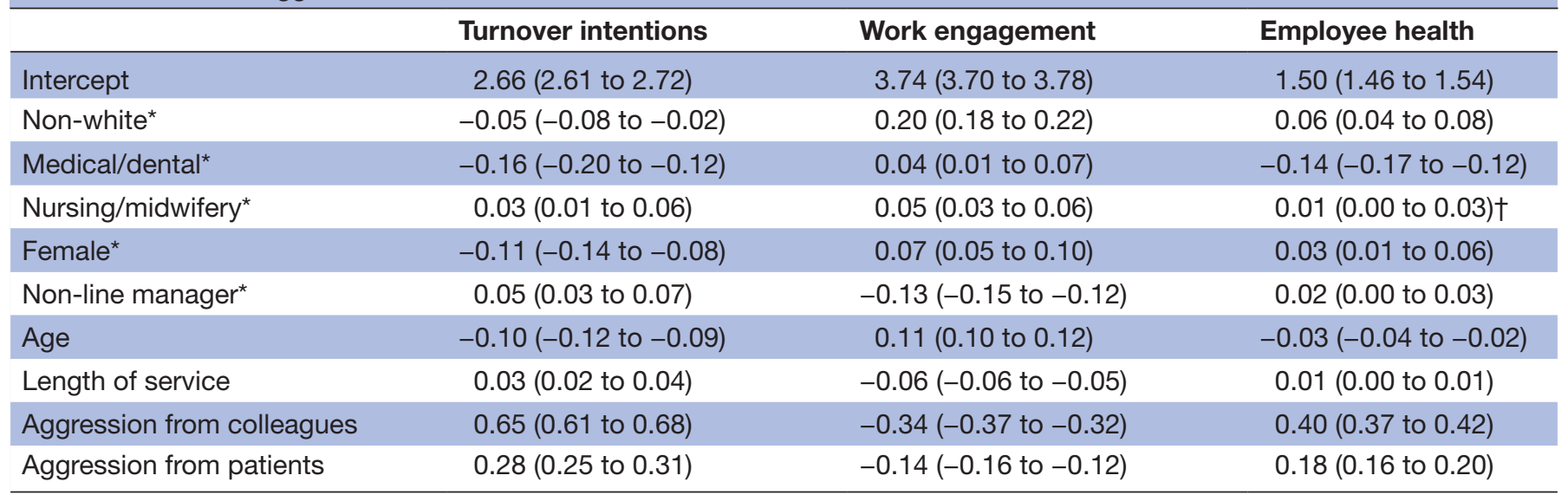

Numbers within parentheses are the $95 \%$ Cls.

${ }^{*}$ Dummy variable: 1 if yes, 0 if no.

†All coefficients significant $(p<0.05)$ except those marked with $†$.

response to the aggression. We found that rates of aggression from both colleagues and patients are high (16\% and $25 \%$, respectively), emphasising how workplace aggression is intrinsic to the delivery of healthcare. We also found that both types of aggression have significant negative effects on employee turnover intentions, work engagement and employee health; however, these results seem to indicate that the effect of aggression from colleagues is more than double the effect of aggression from patients, which supports similar findings from previous research. ${ }^{29} 3334$ However, future research could continue to delve into why these negative effects are stronger. In addition to colleagues potentially having more power over employees' organisational outcomes and employees viewing aggression from colleagues as an organisational injustice (rather than an expected part of their job), ${ }^{34}$ healthcare employees also potentially see their colleagues on a more regular basis than their patients, due to the nature of their work. In addition, aggression from colleagues could feel more personal and harder to excuse. As a result, the impact of aggression from colleagues may be greater, because employees are not as psychologically prepared to experience this type of aggression and may find it harder to cope with. Gaining

Table 5 Effects of aggression moderated by occupational group

\begin{tabular}{|c|c|c|c|}
\hline & Turnover intentions & Work engagement & Employee health \\
\hline Non-white & $-0.05(-0.08$ to -0.02$)$ & 0.20 (0.18 to 0.22$)$ & 0.06 (0.03 to 0.08$)$ \\
\hline Nursing/midwifery & 0.04 (0.01 to 0.07$)$ & 0.05 (0.03 to 0.07$)$ & $0.01(-0.02 \text { to } 0.03)^{\star}$ \\
\hline Female & $-0.11(-0.14$ to -0.08$)$ & 0.07 (0.05 to 0.10$)$ & 0.04 (0.01 to 0.06$)$ \\
\hline Age & $-0.10(-0.12$ to -0.09$)$ & 0.11 (0.10 to 0.12$)$ & $-0.03(-0.04$ to -0.02$)$ \\
\hline Length of service & 0.03 (0.02 to 0.04$)$ & $-0.06(-0.06$ to -0.05$)$ & 0.01 (0.00 to 0.01$)$ \\
\hline Aggression from colleagues & 0.68 (0.62 to 0.75$)$ & $-0.34(-0.39$ to -0.29$)$ & 0.38 (0.33 to 0.43$)$ \\
\hline Aggression from patients & 0.28 (0.22 to 0.34$)$ & $-0.11(-0.15$ to -0.07$)$ & $0.16(0.11$ to 0.20$)$ \\
\hline $\begin{array}{l}\text { Aggr. from patients moderated by medical/ } \\
\text { dental }\end{array}$ & $-0.11(-0.21$ to 0.00$)$ & $-0.04(-0.11 \text { to } 0.04)^{\star}$ & $0.00(-0.07 \text { to } 0.07)^{*}$ \\
\hline $\begin{array}{l}\text { Aggr. from patients moderated by nursing/ } \\
\text { midwifery }\end{array}$ & $0.01(-0.06 \text { to } 0.07)^{\star}$ & $-0.03(-0.08 \text { to } 0.01)^{\star}$ & $0.03(-0.02 \text { to } 0.08)^{*}$ \\
\hline
\end{tabular}

${ }^{*}$ All coefficients significant $(p<0.05)$ except those marked with. 
Table 6 Effects of aggression moderated by gender

\begin{tabular}{|c|c|c|c|}
\hline & Turnover intentions & Work engagement & Employee health \\
\hline Intercept & 2.67 (2.61 to 2.73 ) & 3.75 (3.71 to 3.80 ) & 1.50 (1.46 to 1.54$)$ \\
\hline Non-white & $-0.05(-0.08$ to -0.02$)$ & 0.20 (0.18 to 0.22$)$ & $0.06(0.04$ to 0.08$)$ \\
\hline Nursing/midwifery & $0.03(0.01$ to 0.06$)$ & 0.05 (0.03 to 0.06$)$ & $0.01(0.00 \text { to } 0.03)^{\star}$ \\
\hline Female & $-0.11(-0.14$ to -0.07$)$ & 0.06 (0.03 to 0.08$)$ & 0.04 (0.01 to 0.07$)$ \\
\hline Age & $-0.10(-0.12$ to -0.09$)$ & 0.11 (0.10 to 0.12$)$ & $-0.03(-0.04$ to -0.02$)$ \\
\hline Length of service & 0.03 (0.02 to 0.04$)$ & $-0.06(-0.06$ to -0.05$)$ & 0.01 (0.00 to 0.01$)$ \\
\hline Aggression from colleagues & 0.77 (0.69 to 0.84$)$ & $-0.44(-0.49$ to -0.38$)$ & 0.47 (0.41 to 0.52$)$ \\
\hline Aggression from patients & $0.19(0.12$ to 0.25$)$ & $-0.13(-0.18$ to -0.09$)$ & $0.15(0.10$ to 0.19$)$ \\
\hline $\begin{array}{l}\text { Aggr. from colleagues moderated by } \\
\text { female }\end{array}$ & $-0.14(-0.22$ to -0.07$)$ & $0.12(0.06$ to 0.17$)$ & $-0.08(-0.14$ to -0.03$)$ \\
\hline
\end{tabular}

*All coefficients significant $(p<0.05)$ except those marked with.

additional insight into these processes may allow for more targeted interventions when addressing aggression from colleagues in healthcare settings.

We also examined how the relationship between aggression and these employee outcomes varies by race, gender and occupation, and identified the groups at highest risk in the NHS. Nurses and midwives are more likely to experience both aggression from patients and colleagues than other staff, which is consistent with previous work demonstrating that nurses are at risk for workplace aggression. ${ }^{3}$ Patient contact is a risk factor for aggression, and since nurses administer medication, manage intravenous lines and provide physical and emotion support, they are more likely to be present when patients are in pain, stressed and cognitively impaired. ${ }^{8}$ In addition, we found that women are more likely to experience aggression from patients than men, and of all the racial groups measured, Black employees received the most aggression from both patients and colleagues. Although there are conflicting findings with respect to gender and race and the prevalence of workplace aggression in healthcare, ${ }^{4628}$ our findings were consistent with the broader literature on the negative interpersonal experiences of female and Black employees. ${ }^{37-41}$ In addition, there have been recent findings that racist abuse against NHS staff has nearly tripled over the past few years-suggesting that workplace aggression in the NHS may be racialised. ${ }^{42}{ }^{43}$ Clearly, all employees would benefit from safeguards against

Table 7 Effects of aggression moderated by racial group

\begin{tabular}{lccc}
\hline & Turnover intentions & Work engagement & Employee health \\
\hline Intercept & $2.66(2.61$ to 2.72$)$ & $3.74(3.70$ to 3.78$)$ & $1.50(1.46$ to 1.54$)$ \\
Non-white & $-0.04(-0.07$ to 0.00$)$ & $0.22(0.19$ to 0.24$)$ & $0.06(0.03$ to 0.08$)$ \\
\hline Medical/dental & $-0.16(-0.20$ to -0.12$)$ & $0.04(0.01$ to 0.07$)$ & $-0.14(-0.17$ to -0.12$)$ \\
\hline Nursing/midwifery & $0.03(0.01$ to 0.06$)$ & $0.05(0.03$ to 0.06$)$ & $0.01(0.00 \text { to } 0.03)^{\star}$ \\
\hline Female & $-0.11(-0.14$ to -0.08$)$ & $0.07(0.05$ to 0.10$)$ & $0.04(0.01$ to 0.06$)$ \\
\hline Non-line manager & $0.05(0.03$ to 0.07$)$ & $-0.13(-0.15$ to -0.12$)$ & $0.02(0.00 \text { to } 0.03)^{\star}$ \\
\hline Age & $-0.10(-0.12$ to -0.09$)$ & $0.11(0.10$ to 0.12$)$ & $-0.03(-0.04$ to -0.02$)$ \\
\hline Length of service & $0.03(0.02$ to 0.04$)$ & $-0.06(-0.06$ to -0.05$)$ & $0.01(0.00$ to 0.01$)$ \\
\hline Aggression from colleagues & $0.66(0.62$ to 0.69$)$ & $-0.35(-0.37$ to -0.32$)$ & $0.41(0.39$ to 0.44$)$ \\
Aggression from patients & $0.28(0.25$ to 0.31$)$ & $-0.12(-0.14$ to -0.10$)$ & $0.17(0.15$ to 0.19$)$ \\
\hline $\begin{array}{l}\text { Aggr. from colleagues moderated by } \\
\text { non-white }\end{array}$ & $-0.07(-0.15 \text { to } 0.01)^{\star}$ & $0.05(0.00 \text { to } 0.11)^{\star}$ & $-0.09(-0.15$ to -0.03$)$ \\
$\begin{array}{l}\text { Aggr. from patients moderated by non- } \\
\text { white }\end{array}$ & $0.01(-0.06 \text { to } 0.08)^{\star}$ & $-0.12(-0.17$ to -0.07$)$ & $0.07(0.01$ to 0.12$)$
\end{tabular}

*All coefficients significant $(p<0.05)$ except those marked with. 
Table 8 Effects of aggression moderated by organisational response

\begin{tabular}{lcccc}
\hline & Turnover intentions & Work engagement & Employee health \\
\hline Intercept & $5.26(4.51$ to 6.02$)$ & $2.73(2.30$ to 3.16$)$ & $2.17(1.79$ to 2.55$)$ \\
\hline Non-white & $-0.05(-0.08$ to -0.02$)$ & $0.20(0.18$ to 0.23$)$ & $0.06(0.03$ to 0.08$)$ \\
\hline Medical/dental & $-0.16(-0.20$ to -0.13$)$ & $0.04(0.01$ to 0.07$)$ & $-0.15(-0.17$ to -0.12$)$ \\
\hline Nursing/midwifery & $0.03(0.00$ to 0.06$)$ & $0.05(0.03$ to 0.07$)$ & $0.01(-0.01 \text { to } 0.03)^{\star}$ \\
\hline Female & $-0.11(-0.14$ to -0.08$)$ & $0.07(0.05$ to 0.10$)$ & $0.03(0.01$ to 0.06$)$ \\
\hline Non-line manager & $0.05(0.03$ to 0.07$)$ & $-0.13(-0.15$ to -0.12$)$ & $0.02(0.00 \text { to } 0.03)^{\star}$ \\
\hline Age & $-0.10(-0.12$ to -0.09$)$ & $0.11(0.10$ to 0.12$)$ & $-0.03(-0.04$ to -0.02$)$ \\
\hline Length of service & $0.03(0.02$ to 0.04$)$ & $-0.06(-0.06$ to -0.05$)$ & $0.01(0.00$ to 0.01$)$ \\
\hline Aggression from colleagues & $0.21(-1.10 \text { to } 1.53)^{\star}$ & $0.29(-0.72 \text { to } 1.29)^{*}$ & $-0.61(-1.61 \text { to } 0.39)^{\star}$ \\
\hline Aggression from patients & $1.80(0.74$ to 2.86$)$ & $-0.25(-0.98 \text { to } 0.47)^{\star}$ & $1.35(0.63$ to 2.06$)$ \\
\hline Organisational response & $-0.72(-0.93$ to -0.51$)$ & $0.28(0.16$ to 0.40$)$ & $-0.19(-0.29$ to -0.08$)$ \\
\hline Aggr. from colleagues moderated by org. response & $0.12(-0.25 \text { to } 0.49)^{\star}$ & $-0.17(-0.45 \text { to } 0.11)^{\star}$ & $0.28(0.00$ to 0.56$)$ \\
\hline Aggr. from patients moderated by org. response & $-0.43(-0.72$ to -0.13$)$ & $0.03(-0.17 \text { to } 0.23)^{\star}$ & $-0.33(-0.53$ to -0.13$)$ \\
\hline
\end{tabular}

${ }^{*}$ All coefficients significant $(p<0.05)$ except those marked with.

aggression, but our results highlight that best practices may be critically needed for these groups in particular. For the NHS, this includes nurses/midwives, women and Black employees, although these groups may vary for different healthcare systems across the world-highlighting the importance of local risk assessments. Interestingly, in looking at the effect of aggression on turnover intentions, health and engagement, we found mixed results by race, gender and occupation. These individual groups varied on how strong the effect of aggression was on these outcomes; however, there were no clear patterns (see tables 4-6).

Lastly, we examined how organisational responses can impact the relationship between aggression and employee turnover intentions, health and engagement, and how these relationships may differ based on aggression source. An effective organisational response was found to mitigate the negative impact of aggression from patients on employee turnover intentions, as well as the negative impact of aggression from patients and colleagues on employee health. However, our findings also indicate that simply having an effective organisational response does not solve all of the negative effects from workplace aggression, particularly the effects on employee health. As a result, it is important to continue exploring other ways that organisations may be able to address these issues and support their employees, such as adjusting environmental and work design issues, providing education and training on how to minimise and address workplace aggression, creating an antiaggression climate, implementing policies on how to report workplace aggression, and providing counselling and other emotional support services, ${ }^{6} 313244$ and empirically demonstrate their mitigating effects on workplace aggression. In addition, because there are many existing recommendations and guidelines on how to prevent and address workplace aggression in healthcare, it could be beneficial to further examine barriers to implementing these best practices, as well as what impacts the effectiveness of these practices in different healthcare settings (eg, environmental or individual factors).

\section{Study limitations and future directions}

Although this study takes advantage of a large and comprehensive dataset from the NHS, there are still some limitations. For example, the sample is predominately white and female, which may make it harder to draw conclusions about the experiences of the male and non-white staff. However, this is representative of the healthcare workforce in England, and as such, we believe these analyses can still provide useful insight into the experiences of the NHS staff (but may be more limited in transferability to other countries' healthcare workforces that are demographically different from England's). This sample was also limited by the examination of only clinical staff, even though non-clinical staff (eg, receptionists) have also been shown to experience aggression from patients and colleagues. ${ }^{45} 46$ Future research should include non-clinical staff in their analyses and examine how they may differ from clinical staff in how they are impacted by workplace aggression from patients and collages, and how they respond to different organisational practices attempting to address these issues.

Another limitation lies in the cross-sectional data used in this study, which prevents us from making any causal claims about relationships between variables. As a result, future research should more extensively examine these variables over time to get a better idea of the processes behind the relationships we found in this study. For example, what are healthcare employees' 
affective, cognitive and behavioural responses to the aggression they experience, and how does this impact their turnover intentions, health and engagement? Similarly, how do employees perceive organisational responses to aggression in real time and how might these perceptions change over time? Lastly, this study was using secondary data and therefore constrained by the information provided in the 2010 NHS staff survey. For example, with respect to organisational response, the survey questions simply asked about the extent to which the organisation took effective action in response to aggression from patients and colleagues. There was no detail on what these actions were, and future research would benefit from exploring the specific actions that organisations take in response to aggression and if different actions are perceived as more effective than others. In addition, other measures in the survey were developed specifically for the NHS or adapted from existing measures (eg, SF-8), and future research should continue to examine these relationships using validated measures and compare their findings. However, despite these limitations, this study still provides important insights into how organisational responses can impact the relationships between workplace aggression (from patients and colleagues) and turnover intentions, work engagement and health, and sets the foundation to further explore the mechanisms underlying these relationships.

\section{CONCLUSION}

Regardless of employee characteristics (eg, race, gender, occupation), aggression from patients and colleagues have significant negative effects on employee outcomes-particularly aggression from colleagues. Having an effective organisational response to can help ameliorate the negative effects of aggression on employees' health; however, it may not always buffer negative effects on turnover intentions and work engagement. Future research should examine other approaches, as well as how organisational responses and resources may need to differ based on aggression source, in order to continue building on healthcare organisations' efforts to prevent and minimise the impact of workplace aggression.

\section{Author affiliations \\ ${ }^{1}$ Department of Psychological Sciences, Rice University, Houston, Texas, USA ${ }^{2}$ Sheffield University Management School and School of Health and Related Research, The University of Sheffield, Sheffield, UK \\ ${ }^{3}$ Health Systems and Population Health Sciences, University of Houston College of Medicine, Houston, Texas, USA}

Contributors SC, JD, and EBK conceptualised the idea for this paper. JD analysed and interpreted the data. SC and JT conducted the literature search, and SC, JT and WRL drafted the original paper. All authors contributed to the writing of further drafts and have approved the final version. SC is the guarantor.

Funding The authors have not declared a specific grant for this research from any funding agency in the public, commercial or not-for-profit sectors.
Competing interests All authors have completed the Unified Competing Interest form at www.icmje.org/coi_disclosure.pdf (available on request from the corresponding author) and declare: funding from Aston University; no financial relationships with any organisations that might have an interest in the submitted work in the previous three years; no other relationships or activities that could appear to have influenced the submitted work

Patient and public involvement Patients and/or the public were not involved in the design, or conduct, or reporting, or dissemination plans of this research.

Patient consent for publication Not required.

Ethics approval Data used were from the NHS National Staff Survey in 2010. Funding for the original data collection was provided by the Care Quality Commission, but this analysis was not part of the original funding. Secondary data analysis was included in the ethical approval, which was awarded by the North West MREC, approval number 03/8/047. All authors are independent of the funding body. This was secondary data analysis of observational data, and therefore no protocol was produced.

Provenance and peer review Not commissioned; externally peer reviewed.

Data availability statement Data may be obtained from a third party and are not publicly available. Due to the sensitive nature of some of the variables involved, under the terms of the ethical approval the individual-level data cannot be shared. However, an individual-level data set with some sensitive variables removed is available at ukdataservice.ac.uk. Organisational level summaries of all variables are available at nhsstaffsurveys.com.

Open access This is an open access article distributed in accordance with the Creative Commons Attribution Non Commercial (CC BY-NC 4.0) license, which permits others to distribute, remix, adapt, build upon this work non-commercially, and license their derivative works on different terms, provided the original work is properly cited, appropriate credit is given, any changes made indicated, and the use is non-commercial. See: http://creativecommons.org/licenses/by-nc/4.0/.

ORCID iDs

Shannon Cheng http://orcid.org/0000-0002-8245-7316

Jeremy Dawson http://orcid.org/0000-0002-9365-8586

\section{REFERENCES}

1 Mento C, Silvestri MC, Bruno A, et al. Workplace violence against healthcare professionals: a systematic review. Aggress Violent Behav 2020;51:101381.

2 Hoyle LP, Smith E, Mahoney C, et al. Media Depictions of "Unacceptable" Workplace Violence Toward Nurses. Policy Polit Nurs Pract 2018;19:57-71.

3 Kowalczuk K, Krajewska-Kułak E, Sobolewski M. The reciprocal effect of psychosocial aspects on nurses' working conditions. Front Psychol 2017;8:1386.

4 Liu J, Gan Y, Jiang H, et al. Prevalence of workplace violence against healthcare workers: a systematic review and meta-analysis. Occup Environ Med 2019;76:927-37.

5 Shea T, Sheehan C, Donohue R, et al. Occupational violence and aggression experienced by nursing and caring professionals. J Nurs Scholarsh 2017;49:236-43.

6 Hills D, Joyce C. A review of research on the prevalence, antecedents, consequences and prevention of workplace aggression in clinical medical practice. Aggress Violent Behav 2013;18:554-69.

7 Arnetz J, Hamblin LE, Sudan S, et al. Organizational determinants of workplace violence against hospital workers. J Occup Environ Med 2018;60:693-9.

8 Findorff MJ, McGovern PM, Wall M, et al. Risk factors for work related violence in a health care organization. Inj Prev 2004;10:296-302.

9 LeBlanc MM, Kelloway EK. Predictors and outcomes of workplace violence and aggression. J Appl Psychol 2002;87:444-53.

10 Lanctôt N, Guay S. The aftermath of workplace violence among healthcare workers: a systematic literature review of the consequences. Aggress Violent Behav 2014;19:492-501.

11 Lever I, Dyball D, Greenberg N, et al. Health consequences of bullying in the healthcare workplace: a systematic review. J Adv Nurs 2019;75:3195-209.

12 Ünsal Atan S, Baysan Arabaci L, Sirin A, et al. Violence experienced by nurses at six university hospitals in Turkey. J Psychiatr Ment Health Nurs 2013;20:882-9.

13 Najafi F, Fallahi-Khoshknab M, Ahmadi F, et al. Antecedents and consequences of workplace violence against nurses: a qualitative study. J Clin Nurs 2018;27:e116-28. 
14 Yragui NL, Demsky CA, Hammer LB, et al. Linking workplace aggression to employee well-being and work: the moderating role of Family-Supportive supervisor behaviors (FSSB). J Bus Psychol 2017;32:179-96.

15 Houck NM, Colbert AM. Patient safety and workplace bullying: an integrative review. J Nurs Care Qual 2017;32:164-71.

16 Eker HH, Özder A, Tokaç M, et al. Aggression and violence towards health care providers, and effects thereof. Arch Psychiatry Psychother 2012;4:19-29.

17 Roche M, Diers D, Duffield C, et al. Violence toward nurses, the work environment, and patient outcomes. J Nurs Scholarsh 2010;42:13-22.

18 Hassard J, Teoh KRH, Visockaite G, et al. The cost of work-related stress to society: a systematic review. J Occup Health Psychol 2018;23:1-17.

19 Speroni KG, Fitch T, Dawson E, et al. Incidence and cost of nurse workplace violence perpetrated by hospital patients or patient visitors. J Emerg Nurs 2014;40:218-28.

20 Bowers L. Safewards: a new model of conflict and containment on psychiatric wards: Safewards: description of the model. J Psychiatr Ment Health Nurs 2014;21:499-508.

21 Ariza-Montes A, Muniz NM, Montero-Simó MJ, et al. Workplace bullying among healthcare workers. Int J Environ Res Public Health 2013;10:3121-39.

22 Demir D, Rodwell J, Flower R. Workplace bullying among allied health professionals: prevalence, causes and consequences. Asia Pac J Hum Resour 2013;51:392-405.

23 Johnson SL. An ecological model of workplace bullying: a guide for intervention and research. Nurs Forum 2011;46:55-63.

24 Trépanier S-G, Fernet C, Austin S, et al. Work environment antecedents of bullying: a review and integrative model applied to registered nurses. Int J Nurs Stud 2016;55:85-97.

25 Choi SSW, Budhathoki C, Gitlin LN. Co-Occurrence and predictors of three commonly occurring behavioral symptoms in dementia: agitation, aggression, and rejection of care. Am J Geriatr Psychiatry 2017;25:459-68.

26 Duxbury J, Whittington R. Causes and management of patient aggression and violence: staff and patient perspectives. J Adv Nurs 2005;50:469-78.

27 Rodwell J, Demir D. Addressing workplace violence among nurses who care for the elderly. J Nurs Adm 2014;44:152-7.

28 Edward K-I, Stephenson J, Ousey K, et al. A systematic review and meta-analysis of factors that relate to aggression perpetrated against nurses by patients/relatives or staff. J Clin Nurs 2016;25:289-99.

29 Deery S, Walsh J, Guest D. Workplace aggression: the effects of harassment on job burnout and turnover intentions. Employ Soc 2011;25:742-59.

30 Hahn S, Hantikainen V, Needham I, et al. Patient and visitor violence in the General Hospital, occurrence, staff interventions and consequences: a cross-sectional survey. J Adv Nurs 2012;68:2685-99.

31 Health and Safety Authority. Managing the risk of work-related violence and aggression in healthcare. published online, 2014. Available: https://www.hsa.ie/eng/Publications_and_Forms/ Publications/Information_Sheets/Managing_the_Risk_of_Workrelated_Violence_and_Aggression_in_Healthcare_Information_Sheet. html

32 Occupational Safety and Health Administration. Guidelines for preventing workplace violence for healthcare and social service workers, 2016. Available: https://www.osha.gov/Publications/ osha3148.pdf

33 Merecz D, Drabek M, Mościcka A. Aggression at the workplace-psychological consequences of abusive encounter with coworkers and clients. Int J Occup Med Environ Health 2009;22:243-60.

34 Hershcovis MS, Barling J. Comparing victim attributions and outcomes for workplace aggression and sexual harassment. J Appl Psychol 2010;95:874-88.

35 Cooper-Thomas H, Gardner D, O'Driscoll M, et al. Neutralizing workplace bullying: the buffering effects of contextual factors. $J$ Manag Psychol 2013;28:384-407.

$36 \mathrm{Kim} \mathrm{J-H}$, Lee N, Kim JY, et al. Organizational response to workplace violence, and its association with depressive symptoms: a nationwide survey of 1966 Korean EMS providers. J Occup Health 2019;61:101-9.

37 Gabriel AS, Butts MM, Yuan Z, et al. Further understanding incivility in the workplace: the effects of gender, agency, and communion. $J$ Appl Psychol 2018;103:362-82.

38 Gloor JL, Li X, Lim S, et al. An inconvenient truth? Interpersonal and career consequences of "maybe baby" expectations. J Vocat Behav 2018;104:44-58.

39 Rifat K, Özbilgin Mustafa F, Meltem Y. Race discrimination at work in the United Kingdom. In: Race discrimination and management of ethnic diversity and migration at work vol 6. international perspectives on equality, diversity and inclusion. Emerald Publishing Limited, 2019: 107-27.

40 Smith AN, Watkins MB, Ladge JJ, et al. Making the invisible visible: paradoxical effects of intersectional Invisibility on the career experiences of executive black women. AMJ 2019;62:1705-34.

41 Sojo VE, Wood RE, Genat AE. Harmful workplace experiences and women's occupational well-being. Psychol Women $Q$ 2016;40:10-40.

42 Likupe G, Archibong U. Black African nurses' experiences of equality, racism, and discrimination in the National health service. J Psych Issues in Org Culture 2013;3:227-46.

43 Morgan E. "Can I have a white doctor for the operation?": Racist abuse against NHS staff almost triples, ITV News finds. ITV News, 2019. Available: https://www.itv.com/news/2019-10-31/can-i-havea-white-doctor-for-the-operation-racist-abuse-against-nhs-staffalmost-triples-itv-news-finds/

44 Miner KN, Settles IH, Pratt-Hyatt JS, et al. Experiencing Incivility in organizations: the buffering effects of emotional and organizational Support1. J Appl Soc Psychol 2012;42:340-72.

45 Rodwell J, Demir D, Flower RL. The oppressive nature of work in healthcare: predictors of aggression against nurses and administrative staff. J Nurs Manag 2013;21:888-97.

46 Viottini E, Politano G, Fornero G, et al. Determinants of aggression against all health care workers in a large-sized university hospital. BMC Health Serv Res 2020;20:215.

47 Schaufeli WB, Bakker AB, Salanova M. The measurement of work engagement with a short questionnaire: a cross-national study. Educ Psychol Meas 2006;66:701-16.

48 Ware JE, Kosinski M, Dewey JE, et al. How to score and interpret single-item health status measures: a manual for users of the SF-8 health survey. QualityMetric, 2001.

49 LeBreton JM, Senter JL. Answers to 20 questions about interrater reliability and interrater agreement. Organ Res Methods 2008;11:815-52. 